\title{
Carnation Vacuum Freezing Test
}

\author{
Dayu Zheng, Xiang Li*, Haifeng Yu and Li Wang \\ School of Energy and Architecture Engineering of Harbin Commercial University, Harbin, 150028, China \\ ${ }^{*}$ Corresponding author
}

\begin{abstract}
According to the market of carnation flowers is processed by vacuum drying, focuses on the flower color retention treatment. By the contrast test analysis, factors to influence on the quality of flowers were obtained, and to improve, for flowers on the systematic and reasonable ground treatment.
\end{abstract}

Keywords-carnation; drying; vacuum; color retention

\section{INTRODUCTION}

The poem back to Leroy, You tong Fang Jinqi feast. Green jade draw arbitrary section thin, light purple flowers round with carved silk fabrics. Don't put the wind falling early; we should cherish the partial rain. To the beauty clothes embroidered, more good to stay off $\mathrm{Fu}$ Chan Juan. Since ancient times, flowers are closely related to people's lives. Carnation, aka lion carnation, carnation, carnation, carnation, Dianthus Caryophyllaceous genus of plants, distribution in the temperate regions of Europe and China, Fujian, Hubei, native to the Mediterranean region, is one of the flowers of the world's most widely used. Carnation includes many variants and hybrids in the greenhouse, almost continuous flowering. In 1907, starting with pink carnations as a symbol of mother's day, so it is often regarded as the flowers to my mother. Flower life is so short a sigh of regret. Flowers, as a commodity, the short life not only for the production and sale of huge losses, but also a great impact on the value of its viewing. Although a variety of fresh flower preservation technology to a certain extent, extend its life, but still can not make it more time to keep and maintain a high ornamental value [1]. All kinds of paper flowers, silk flower, artificial flowers although beautiful and can be kept for a long time, but it is not true, the natural advantages of flowers. How can we get a kind of flower that has the real, natural, and long-term preservation of flowers, so people focus on the focus of the fresh flowers of the dry. As a result, some fresh flowers drying technology came into being.

In recent years, the flower industry is rapid development of dry in the world. French dry flower market is flourishing. Flowers begin to sales of dried flower products, dry flower processing technology and research having been conducted, the basic realization of the industrial production [2]. In many markets in Australia, the flower shop has dry flowers for sale.

The society for the main varieties of drying flowers such as rose and peony, but the symbol of motherly love carnation was overlooked by most people. This experiment adopts carnation as the research object, focuses on the color of the carnation.

Freeze drying is a kind of technology which is used to dry. It is a kind of technology which will be dry and quickly frozen under low temperature. Then, the frozen water molecules directly sublimation into the process of water vapor escapes [3].
Material is always in a low temperature (frozen state), while the ice crystals are evenly distributed in the material, the sublimation process will not be due to dehydration and condensation phenomenon, to avoid the water vapor generated foam, oxidation and other side effects. Dry matter is a dry sponge, the volume of the basic, very soluble in water and the restoration of the original state. To the greatest extent, the physical and biological aspects of the dry matter are prevented from the physical and biological aspects of the [4].

In this paper, we use the vacuum freeze dryer of Harbin University of Commerce to test and use all kinds of medicine collocation, and then get the optimal proportion and time arrangement of frozen dried medicine.

The basic steps are as follows: the vacuum freeze dryer is started and the basic step is the basic step:

1) start step: start vacuum freezing dryer - start compressor - click on the freeze drying chamber refrigeration button returns the data view - stay shelf temperature to - 40 degrees Celsius and cold trapping and cooling to be cold trap temperature to 50 DEGC - open vacuum pump - observe the vacuum degree reached 30Pa click on the following partition temperature control button, then according to the procedures set of automatic running;

2) Shutdown steps: open the water inlet valve - close the vacuum pump - shut down the compressor - wait about 5 minutes - off the freeze drying chamber refrigeration.

The diagram below is a vacuum freezing diagram:

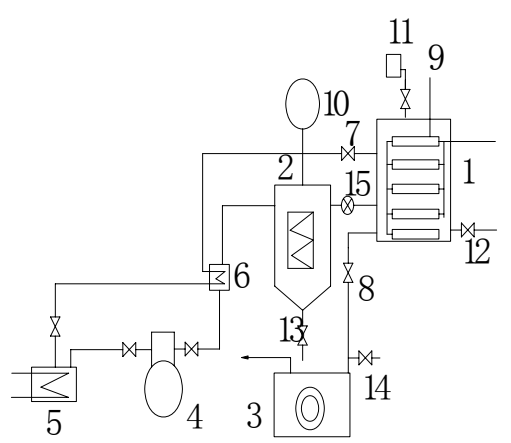

FIGURE I. REFRIGERATION DIAGRAM

1 - FREEZE DRYING BOX 2 - CONDENSER 3-VACUUM PUMP 4 - REFRIGERATION COMPRESSOR 5-COOLER 6 HEAT EXCHANGER 7-FREEZE-DRIED CONDENSER BOX 8 THROTTLE VALVE 9-PARTITION INDICATING 10-CONDENSING TEMPERATURE INDICATOR 11-GAUGE

12-FREEZE-DRYING TANK GAS DISCHARGING VALVE 13-CONDENSER OUTLET 14-VACUUM PUMP ON THE PORTS 15- EXPANSION VALVE 
The refrigeration cycle basic steps: compressor for compressing the refrigerant become through refrigerant steam with high temperature and pressure (6) exchanger for heat exchange, (2) condenser refrigerant steam will be cryogenically cooled high-pressure liquid refrigerant entering, after (15) expansion valve throttling backward in the frozen dry box and material of heat exchanger, after exchanging heat of the refrigerant vapor through (6) heat exchanger and the compressor exhaust heat into (5) water cooler to cool into the compressor, to a refrigeration cycle. This process takes advantage of refrigeration cycle.

\section{TEST METHOD}

Chemical protection method for maintaining or changing the chemical structure and properties of the original pigment by chemical reaction with the chemical reaction of the chemical reagent and plant. Commonly used to protect the color of the pharmaceutical has the cream of the cream, citric acid, sulfuric acid, sulfuric acid, aluminum sulfate, alum, tin chloride, zinc oxide, sucrose, etc.

In this experiment, the experimental formula of calcium chloride and citric acid was used to deal with the different concentrations of different concentrations. Test according to the proportion of its own.

1) color: $15 \%$ calcium chloride $+5 g$ citric acid were treated at different temperatures;

2) Softening treatment: $15 \%$ glycerol solution at 10, 15, 20, 25 , 30, respectively, in the environment of $2 \mathrm{~h}$;

3) pre-freezing treatment: the pre freezing temperatures were selected at room temperature $20^{\circ} \mathrm{C},-30^{\circ} \mathrm{C},-35^{\circ} \mathrm{C},-40^{\circ} \mathrm{C}$, $-45^{\circ} \mathrm{C},-50^{\circ} \mathrm{C}$, respectively.

And the temperature time schedule for the vacuum freeze drying:

According to the set time of concentration, experimental research, draw the following several sets of data, and preliminary quantitative color according to the four colors Handbook.

TABLE I. TEMPERATURE AND CORRESPONDING TIME

\begin{tabular}{|c|c|}
\hline \multicolumn{2}{|c|}{ Temperature And Corresponding Time } \\
\hline Temperature/ ${ }^{\circ} \mathrm{C}$ & Time $/ \mathrm{h}$ \\
\hline-30 & 2 \\
\hline-25 & 2 \\
\hline-10 & 2 \\
\hline 0 & 2 \\
\hline
\end{tabular}

\begin{tabular}{|l|l|}
\hline \multicolumn{2}{|c|}{ Temperature And Corresponding Time } \\
\hline \multicolumn{2}{|c|}{${\text { Temperature } /{ }^{\circ} \mathrm{C}}^{\text {Time } / \mathbf{h}}$} \\
\hline 10 & 2 \\
\hline 20 & 4 \\
\hline 30 & 3 \\
\hline 40 & 5 \\
\hline
\end{tabular}

\section{SUMMARY OF EXPERIMENTAL DATA}

TABLE II. TEST DATA ONE

\begin{tabular}{|l|l|l|}
\hline \multicolumn{3}{|c|}{ Before Processing The Parameters } \\
\hline Stem width/mm & Quality/g & Processing color \\
\hline $30+12 * 0.02$ & 9.342 & M100Y80C10 \\
\hline $30+18 * 0.02$ & 8.453 & M100Y100C10 \\
\hline $30+10 * 0.02$ & 9.370 & M100Y80C10 \\
\hline $30+23 * 0.02$ & 7.667 & M100Y100C10 \\
\hline
\end{tabular}

\begin{tabular}{|l|l|l|}
\hline \multicolumn{3}{|c|}{ After Processing Parameters } \\
\hline \multicolumn{1}{|c|}{ Stem width/mm } & Quality/g & Processing color \\
\hline $30+9 * 0.02$ & 3.688 & M100Y100C15 \\
\hline $30+14 * 0.02$ & 3.177 & M100Y100C10 \\
\hline $30+7 * 0.02$ & 2.924 & M100Y80C40 \\
\hline $30+26 * 0.02$ & 2.587 & M100Y100C40 \\
\hline
\end{tabular}

TABLE III. TEST DATA TWO

\begin{tabular}{|l|l|l|}
\hline \multicolumn{3}{|c|}{ Before Processing The Parameters } \\
\hline \multicolumn{1}{|c|}{ Stem width/mm } & \multicolumn{1}{|c|}{ Quality/g } & Processing color \\
\hline $30+19 * 0.02$ & 6.694 & M100Y80C10 \\
\hline $30+16 * 0.02$ & 10.127 & M100Y80C10 \\
\hline $30+1 * 0.02$ & 8.949 & M100Y80C25 \\
\hline $30+32 * 0.02$ & 7.392 & M100Y100C10 \\
\hline
\end{tabular}

\begin{tabular}{|l|l|l|}
\hline \multicolumn{3}{|c|}{ After Processing Parameters } \\
\hline Stem width/mm & Quality/g & Processing color \\
\hline $30+10 * 0.02$ & 1.907 & M100Y80C50 \\
\hline $30+10 * 0.02$ & 3.792 & M100Y100C40 \\
\hline $30+15 * 0.02$ & 4.222 & M100Y100C35 \\
\hline $30+20 * 0.02$ & 2.804 & M100Y100C25 \\
\hline
\end{tabular}

TABLE IV. TEST DATA THREE:

\begin{tabular}{|l|l|l|}
\hline \multicolumn{3}{|c|}{ Before Processing The Parameters } \\
\hline \multicolumn{1}{|c|}{ Stem width/mm } & Quality/g & Processing color \\
\hline $40+32 * 0.02$ & 8.459 & M100Y80C10 \\
\hline $40+1 * 0.02$ & 9.278 & M100Y80C10 \\
\hline $30+17 * 0.02$ & 9.831 & M100Y80C10 \\
\hline $40+6 * 0.02$ & 7.665 & M100Y100C10 \\
\hline
\end{tabular}

\begin{tabular}{|l|l|l|}
\hline \multicolumn{3}{|c|}{ After Processing Parameters } \\
\hline Stem width/mm & Quality/g & Processing color \\
\hline $30+10 * 0.02$ & 3.132 & M100Y80C10 \\
\hline $37+18 * 0.02$ & 3.568 & M100Y80C30 \\
\hline $30+15 * 0.02$ & 3.419 & M100Y80C25 \\
\hline $30+20 * 0.02$ & 2.765 & M100Y80C40 \\
\hline
\end{tabular}

The following figure is the experiment before and after comparison: 
By comparing the test, drug choice of basic fresh carnation results wanted. The preliminary experimental study on vacuum freeze-drying of fresh flowers, of red carnations experimental flower material pre freezing process temperature and freeze drying process, respectively the different experimental verification [5].

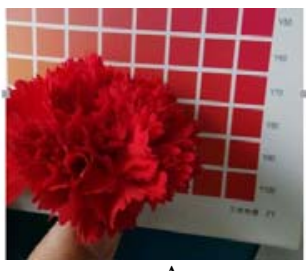

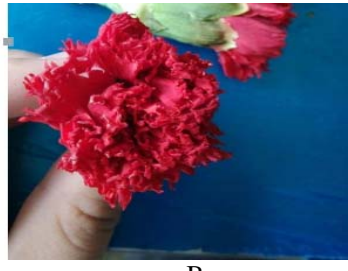

FIGURE II. FRESH CAMATION (A) AND DRIED CAMATION (B) COMPARISON CHART

\section{CONCLUSIONS}

Through the experiment, the vacuum freeze drying flowers can be used to maintain the shape, color and fragrance of the flowers, and the color of the flower is almost unchanged after drying. The results show that the use of vacuum freeze drying technology is a feasible method for drying flowers. We also need to further by the line of research, further optimization of the freeze-drying process, reduce energy consumption, and research stem carnation petals hardness brittle degree, to achieve a better preservation and reduce the brittle failure.

\section{ACKNOWLEDGMENT}

Project source: Harbin University of Commerce graduate student innovation fund project.

Project number: YJSCX2015-351HSD.

\section{REFERENCE}

[1] Zhong Lijuan, Zhu Wenxue, Dong Tieyou, etal. Study on the drying process of peony flowers [J]. food science, 2005, (26): 52-57.

[2] Chen Wei, Gastb K L B, Smithey S. The effects of different freeze-drying processes on the moisture content. Color and physical strength of roses and carnations[J]. Scientia Horticulturae, 2004,44:71-78.

[3] Maskan M. Kinetic of color change of kiwifruits during hot air and micro wave drying[J]. Journal of Food Engineering, 2001,48:169-175.

[4] pay Xiguang, Dong Ying, Ma Haile. Journal of the University of food vacuum freeze drying research [J]. Jiangsu Institute of Technology (NATURAL SCIENCE EDITION), 2001,22 (4): 19-23. 